\title{
Heterogeneous kinetics, products, and mechanisms of ferulic acid particles in the reaction with $\mathrm{NO}_{3}$ radicals
}

\author{
Changgeng Liu ${ }^{\mathrm{a}}{ }^{\mathrm{b}},{ }^{*}$, Peng Zhang ${ }^{\mathrm{b}}$, Xiaoying Wen ${ }^{\mathrm{a}}$, Bin $\mathrm{Wu}^{\mathrm{a}}$ \\ a School of Resources and Environmental Engineering, Panzhihua University, Panzhihua 617000, China \\ ${ }^{\mathrm{b}}$ Research Center for Eco-Environmental Sciences, Chinese Academy of Sciences, Beijing 100085, China
}

\section{H I G H L I G H T S}

- Six degradation products of ferulic acid by $\mathrm{NO}_{3}$ radicals are identified.

- Reaction mechanisms of particulate ferulic acid with $\mathrm{NO}_{3}$ radicals were proposed.

- Effective rate constant was determined by a mixed-phase relative rate method.

- Uptake coefficient of $\mathrm{NO}_{3}$ radicals on ferulic acid particles was $0.17 \pm 0.02$.

\section{A R T I C L E I N F O}

\section{Article history:}

Received 27 July 2016

Received in revised form

16 December 2016

Accepted 19 December 2016

Available online 21 December 2016

\section{Keywords:}

Methoxyphenols

$\mathrm{NO}_{3}$ radicals

Heterogeneous reaction

Aerosol mass spectrometry
G R A P H I C A L A B S T R A C T

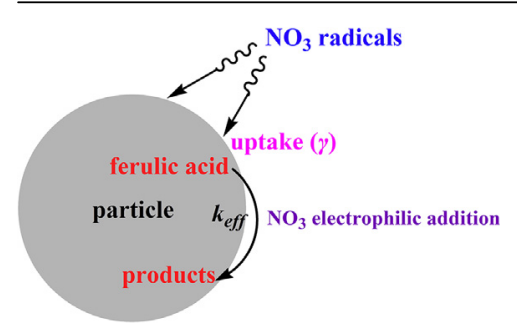

\begin{abstract}
A B S T R A C T
Methoxyphenols, as an important component of wood burning, are produced by lignin pyrolysis and considered to be the potential tracers for wood smoke emissions. In this work, the heterogeneous reaction between ferulic acid particles and $\mathrm{NO}_{3}$ radicals was investigated. Six products including oxalic acid, 4-vinylguaiacol, vanillin, 5-nitrovanillin, 5-nitroferulic acid, and caffeic acid were confirmed by gas chromatography-mass spectrometry (GC-MS). In addition, the reaction mechanisms were proposed and the main pathways were $\mathrm{NO}_{3}$ electrophilic addition to olefin and the meta-position to the hydroxyl group. The uptake coefficient of $\mathrm{NO}_{3}$ radicals on ferulic acid particles was $0.17 \pm 0.02$ and the effective rate constant under experimental conditions was $(1.71 \pm 0.08) \times 10^{-12} \mathrm{~cm}^{3}$ molecule ${ }^{-1} \mathrm{~s}^{-1}$. The results indicate that ferulic acid degradation by $\mathrm{NO}_{3}$ can be an important sink at night.
\end{abstract}

๑) 2017 Elsevier Ltd. All rights reserved.

\section{Introduction}

Wood smoke emissions are as a major source of air pollution and can contribute more than $50 \%$ of the $\mathrm{PM}_{10}$ mass in the residential area (Bari et al., 2010). The increasing concentration of aerosols has subsequent adverse effects on ambient air quality, climate, and human health (Naeher et al., 2007). Generally, exposure to wood smoke is often correlated with respiratory diseases

\footnotetext{
* Corresponding author. School of Resources and Environmental Engineering, Panzhihua University, Panzhihua 617000, China.
}

E-mail address: changwyx@163.com (C. Liu). due to the inhalable size of the particles emitted by wood burning (Ezzati and Kammen, 2002; Naeher et al., 2007; Bolling et al., 2009).

Methoxyphenols produced by lignin pyrolysis are known as the potential tracers for wood smoke emissions, which widely exist in ambient atmospheric samples in high concentrations (Nolte et al., 2001; Alves et al., 2011). In recent years, the homogeneous reactivities of some methoxyphenols toward $\mathrm{OH}$ radicals (CoeurTourneur et al., 2010; Lauraguais et al., 2012, 2014a; Yee et al., 2013), $\mathrm{NO}_{3}$ radicals (Lauraguais et al., 2016; Yang et al., 2016; Zhang et al., 2016), chlorine atoms (Lauraguais et al., 2014b), and $\mathrm{O}_{3}$ (Ofner et al., 2011) have been investigated, and these studies mainly reported their reaction kinetics and the formation of secondary organic aerosols (SOA). Additionally, Net et al. (2010, 2011) 
and O'Neill et al. (2014) have reported the heterogeneous ozonation of several methoxyphenols adsorbed on model particles. In our previous study, the kinetics, products, and mechanisms of heterogeneous reactions between three particulate methoxyphenols and $\mathrm{NO}_{3}$ radicals have been reported (Liu et al., 2012a). All these show that the chemical behaviors of methoxyphenols have been attracted great attention. However, the heterogeneous reactivities of their suspended particles toward gaseous oxidants still need to be further explored.

Ferulic acid (Fig. 1), a type of methoxyphenols, is a representative unsaturated acid emitted from lignin pyrolysis (Nolte et al., 2001; Alves et al., 2011). However, its reactivity in the atmosphere has not been studied yet. It is well known that the chemical processing of organics would result in further influences on human health, climate, and air quality (Knopf et al., 2011). Therefore, from a health point of view, the knowledge on its chemical behaviors has significant impacts on assessing its toxicity and safety.

Ferulic acid contains benzene ring and olefinic $\mathrm{C}=\mathrm{C}$ bond, which are both the favored sites for the reaction with $\mathrm{NO}_{3}$ radicals (Knopf et al., 2011; Liu et al., 2012a; Lauraguais et al., 2016; Yang et al., 2016; Zhang et al., 2016). $\mathrm{NO}_{3}$ radicals are the dominant oxidant in the nighttime with similar oxidative power as hydroxyl radicals (Karagulian and Rossi, 2005), and control the nighttime chemical processing of organics in the troposphere (Wayne et al., 1991). Its concentration in the troposphere could reach $\sim 1 \times 10^{10}$ molecules $\mathrm{cm}^{-3}$ (Atkinson, 1991). For this reason, the aim of this work was to explore the heterogeneous kinetics and products of particulate ferulic acid degradation by $\mathrm{NO}_{3}$ radicals. The reaction products were identified by gas chromatography mass spectrometry (GCMS) and the reaction mechanisms were illustrated.

\section{Experimental section}

\subsection{Experimental setup}

The scanning mobility particle sizer (SMPS) and the aerosol generator equipped with two tandem quartz tubes have been described in detail elsewhere (Liu et al., 2012a). Ferulic acid particles were generated through homogeneous nucleation. Azelaic acid was employed to produce nuclei due to its limited reactivity toward $\mathrm{NO}_{3}$ radicals (Liu et al., 2012b). Azelaic acid in the first tube was vaporized and then nucleated in a nitrogen stream to produce nuclei through temperature gradient. A nitrogen stream with a flow rate of $0.8 \mathrm{~L} \mathrm{~min}^{-1}$ flowed through the first tube, bringing the nuclei into the second tube, where azelaic acid nuclei were coated by ferulic acid vapor. The mean diameter and mass concentration of ferulic acid particles were $\sim 330 \mathrm{~nm}$ and $438 \pm 22 \mu \mathrm{g} \mathrm{m}^{-3}$, respectively, measured by SMPS. The thickness of the coating was $43 \mathrm{~nm}$ for ferulic acid, calculated according to the size distributions of particles before and after being coated by ferulic acid.

The reaction was performed in a chamber with a volume of $\sim 180 \mathrm{~L}$ and its description was illustrated elsewhere (Liu et al., 2012a). The experiments were conducted under the ambient pressure at room temperature $(298 \mathrm{~K})$. The relative humidity in the reaction chamber was approximately $5 \%$, estimated from the residual filtered air in the chamber. When the concentration of ferulic acid particles reached the desired value, isoprene was

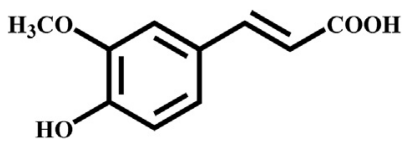

Fig. 1. The chemical structure of ferulic acid. injected into the reaction chamber. The concentration changes of gaseous isoprene and particulate ferulic acid in the chamber were monitored synchronously by an online atmospheric gas analysis mass spectrometer (QIC-20-HAL3F-RC, Hiden) and a real-time vacuum ultraviolet photoionization aerosol time-of-flight mass spectrometer (VUV-ATOFMS), respectively. The initial concentration of isoprene in the chamber was $\sim 1.0 \times 10^{14}$ molecules $\mathrm{cm}^{-3}$, measured by detecting the mass peak at $\mathrm{m} / \mathrm{z} 67\left(\mathrm{C}_{5} \mathrm{H}_{7}^{+}\right)$. Subsequently, a nitrogen stream with a flow rate of $0.8 \mathrm{~L} \mathrm{~min}^{-1}$ passed through a flask containing $\mathrm{N}_{2} \mathrm{O}_{5}$ powders and brought gaseous $\mathrm{N}_{2} \mathrm{O}_{5}$ into the chamber, which produced $\mathrm{NO}_{3}$ radicals by thermal decomposition at the room temperature $(298 \mathrm{~K})$. The concentrations of $\mathrm{NO}_{3}$ radicals in the experiment were $(3.6-8.3) \times 10^{9}$ molecules $\mathrm{cm}^{-3}$, calculated based on the loss rates of isoprene. The wall losses of ferulic acid and isoprene in the absence of oxidants for $300 \mathrm{~s}$ were $\sim 5 \%$, monitored with VUV-ATOFMS and the atmospheric gas analysis mass spectrometer, respectively.

The decay of ferulic acid particles was monitored by a homebuilt VUV-ATOFMS. The detailed description of VUV-ATOFMS has been presented elsewhere (Shu et al., 2008). It consists of a source chamber, a differential chamber, and a detection chamber. A copper heater $(-503 \mathrm{~K})$ with a diameter of $8 \mathrm{~mm}$ placed in the detection chamber is used to vaporize the particles. The nascent organic vapor is photoionized by VUV light emitted from a VUV light lamp, of which the wavelength and a photon flux are $\sim 123.6 \mathrm{~nm}$ and $\sim 5 \times 10^{14}$ photons $\mathrm{s}^{-1}$, respectively. The concentration of ferulic acid particles was linear to the signal intensity of the molecular ion mass peak measured by VUV-ATOFMS, thus the decay rate of signal intensity was equal to the decay rate of ferulic acid concentration (Shu et al., 2008).

\subsection{GC-MS analysis}

In order to assign the TOF mass spectra of reaction products, GCMS analysis was performed to identify the products formed in the reaction of surface-bound ferulic acid with $\mathrm{NO}_{3}$ radicals. The detailed descriptions of sample preparation and GC-MS analysis have been presented elsewhere (Liu et al., 2012a). GC-MS analysis was conducted before and after derivatization with BSTFA. Each derivatization solution was prepared by incubating the mixture of $\sim 2 \mathrm{~mL}$ extracted solution and $\sim 200 \mu \mathrm{L}$ BSTFA for $\sim 24 \mathrm{~h}$ at room temperature. The reaction products were analyzed by GC-MS in the total ion chromatogram (TIC) mode and identified by comparing their electron ionization (EI) mass spectra with those from a Mass Spectral Library [the National Institute of Standards and Technology (NIST) 2005]. Compared with the available mass spectra in the NIST 2005 library, the product with the match rate over $90 \%$ could be identified. The mass range from 30 to $500 \mathrm{amu}$ was used in the process of data acquisition.

\subsection{Chemicals}

Ferulic acid (Acros, 99\%), bis(trimethylsilyl)trifluoroacetamide (BSTFA) [Sigma-Aldrich, containing 10\% trimethylchlorosilane (TMCS)], dichloromethane (J. T. Baker Co., chromatographic grade) were used in the experiments. Azelaic acid (99\%), fuming nitric acid (95\%), $\mathrm{P}_{2} \mathrm{O}_{5}$ (98\%), absolute ethyl alcohol (99.7\%) were from Sinopharm Chemical Reagent Co., Ltd. Nitrogen (99.99\%) and nitrogen dioxide (15.9\%) were from Beijing Huayuan Gas Chemical Industry Co., Ltd.

\section{Results and discussion}

In this work, the maximum average concentrations of $\mathrm{N}_{2} \mathrm{O}_{5}$ and $\mathrm{NO}_{2}$ were $\sim 5.5 \times 10^{12}$ and $\sim 3.1 \times 10^{13}$ molecules $\mathrm{cm}^{-3}$, respectively, 
estimated by thermal decomposition rate of $\mathrm{N}_{2} \mathrm{O}_{5}$ at $298 \mathrm{~K}$ (Ide et al., 2008) and the loss rates of isoprene. Knopf et al. (2011) indicated that the uptake coefficient of $\mathrm{N}_{2} \mathrm{O}_{5}$ on methoxyphenols was $\sim 3$ orders of magnitude smaller than that of $\mathrm{NO}_{3}$ radicals, thus the degradation of ferulic acid by $\mathrm{N}_{2} \mathrm{O}_{5}$ was not taken into account. In a single experiment, no obvious decay and product were observed by VUV-ATOFMS when particulate ferulic acid was exposed to $\mathrm{NO}_{2}$ with a concentration of $\sim 5.5 \times 10^{13}$ molecules $\mathrm{cm}^{-3}$ for $600 \mathrm{~s}$. Since the maximum acquisition time for kinetic data in the experiments was less than $300 \mathrm{~s}$, the degradation of ferulic acid by $\mathrm{NO}_{2}$ was also ignored in this work.

\subsection{Reaction products}

The products detected and identified by GC-MS are listed in Table 1. As shown in Fig. 2A, the mass peak at m/z 194 was resulted from the molecular ion of ferulic acid. The time-of-flight (TOF) mass spectrum of the products obtained by exposing ferulic acid particles to $\mathrm{NO}_{3}$ radicals for $150 \mathrm{~s}$ is shown in Fig. 2B. Its mass peaks at $\mathrm{m} / \mathrm{z} 197$ and 239 were tentatively assigned to be the molecular ions of 5-nitrovanillin and 5-nitroferulic acid, respectively, based on GCMS analysis. Additionally, other four products including oxalic acid (after derivatization), 4-vinylguaiacol, vanillin, and caffeic acid (after derivatization) were confirmed by GC-MS, and their retention times were 5.1, 5.7, 7.7, and 12.7 min (Table 1), respectively. Their corresponding mass spectra from GC-MS analysis are shown in Fig. 3. In this work, some products were not detected by VUVATOFMS while identified by GC-MS; the reason might be the different detection limits of the two instruments (Gao et al., 2008). Besides, it was speculated that the impact of VUV photoionization process on the products could be ignored due to few fragments observed in the TOF mass spectra of products during experimental process.

$\mathrm{Ng}$ et al. (2008) reported that an organic acid compound $\left(\mathrm{C}_{5} \mathrm{H}_{7} \mathrm{~N}_{2} \mathrm{O}_{9}^{-}, \mathrm{m} / \mathrm{z} 239\right)$ was detected as one of the SOA products for the reaction of gaseous isoprene with $\mathrm{NO}_{3}$ radicals, which has a same molecular weight as that of 5-nitroferulic acid. In order to investigate the potential contributions of SOA products to the mass spectra acquired in this work, the reaction between gaseous

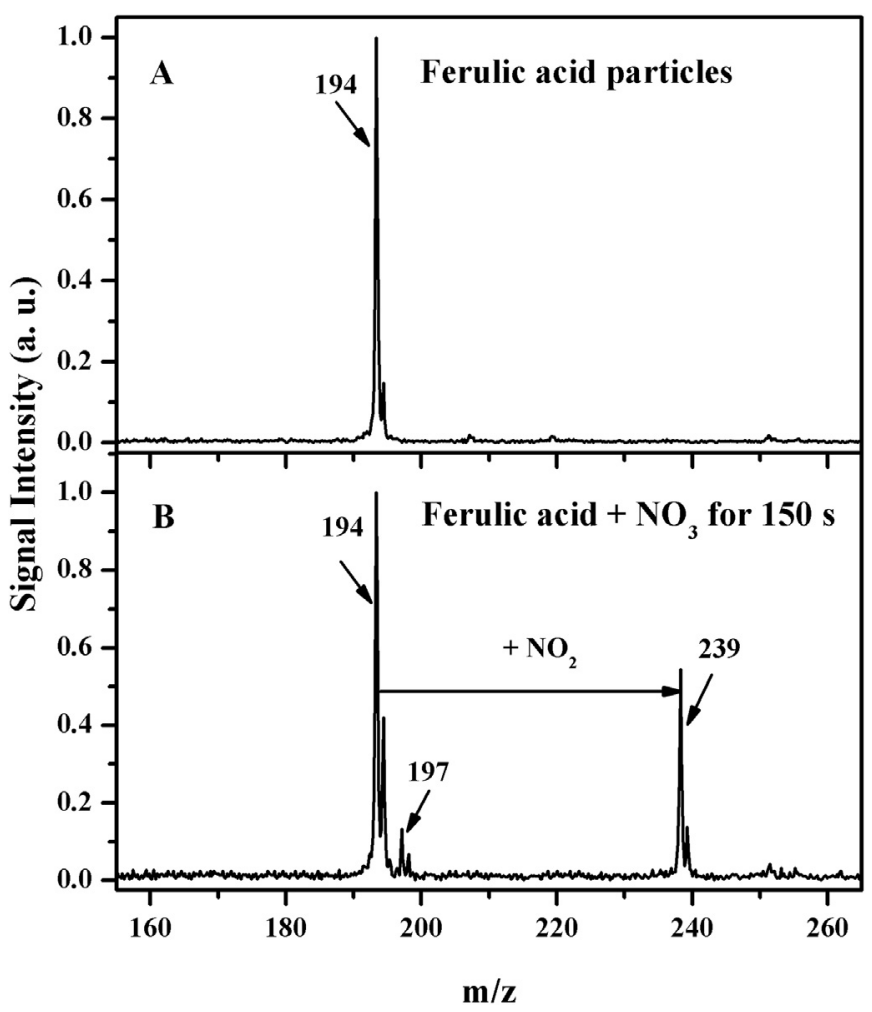

Fig. 2. TOF mass spectra of particulate ferulic acid (A) and its oxidation products for the reaction with $\mathrm{NO}_{3}$ radicals (B). The spectrum shown in Fig. 1B was acquired $150 \mathrm{~s}$ after $\mathrm{NO}_{3}$ radicals were introduced into the reaction chamber. The acquisition time for each mass spectrum was $10 \mathrm{~s}$. The TOF mass spectra were both normalized to their most intense peaks at $\mathrm{m} / \mathrm{z} 194$.

isoprene and $\mathrm{NO}_{3}$ radicals was conducted alone and in-situ observed by VUV-ATOFMS for $300 \mathrm{~s}$. The concentration of isoprene was the same as that used for the kinetic experiments. The results showed that no obvious mass peaks were detected by VUVATOFMS, which might be resulted from the low sensitivity of VUV-

Table 1

Identified products of the heterogeneous reaction between ferulic acid and $\mathrm{NO}_{3}$ radicals.

\begin{tabular}{|c|c|c|c|c|c|c|}
\hline Number & Name & Structure & $\mathrm{RT}(\min )$ & $\mathrm{MW}\left(\mathrm{g} \mathrm{mol}^{-1}\right)$ & Formula & Standard confirmed \\
\hline I & Oxalic acid ${ }^{*}$ & & 5.1 & 90 & $\mathrm{C}_{2} \mathrm{H}_{2} \mathrm{O}_{4}$ & $\sqrt{ }$ \\
\hline II & 4-Vinylguaiacol & $\mathrm{H}_{3} \mathrm{CC}$ & 5.7 & 150 & $\mathrm{C}_{9} \mathrm{H}_{10} \mathrm{O}_{2}$ & $\sqrt{ }$ \\
\hline III & Vanillin & $\mathrm{H}_{3} \mathrm{C}$ & 7.7 & 152 & $\mathrm{C}_{8} \mathrm{H}_{8} \mathrm{O}_{3}$ & $\sqrt{ }$ \\
\hline IV & 5-Nitrovanillin & & 9.9 & 197 & $\mathrm{C}_{8} \mathrm{H}_{7} \mathrm{NO}_{5}$ & $\sqrt{ }$ \\
\hline V & 5-Nitroferulic acid & & 11.9 & 239 & $\mathrm{C}_{10} \mathrm{H}_{9} \mathrm{NO}_{6}$ & - \\
\hline VI & Caffeic acid* & & 12.7 & 180 & $\mathrm{C}_{9} \mathrm{H}_{8} \mathrm{O}_{4}$ & $\sqrt{ }$ \\
\hline
\end{tabular}

RT is the retention time, and MW is the molecular weight of compounds. Asterisks denote the products only identified by GC-MS analysis after derivatization by BSTFA. 

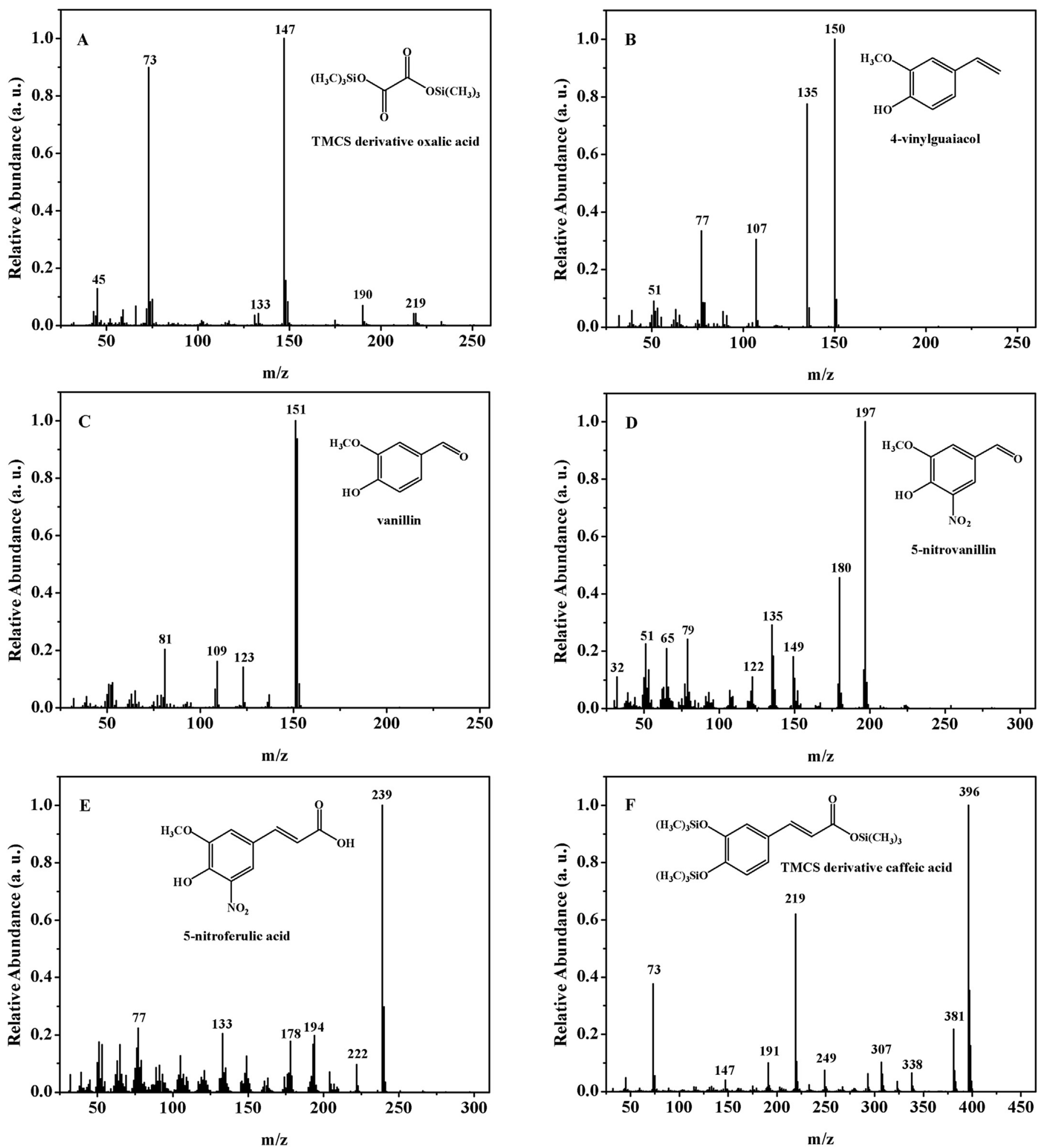

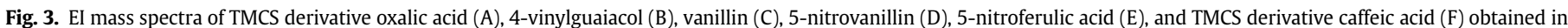
the experiments.

ATOFMS toward the particles with small diameters (<70 nm) (Yang et al., 2010). The similar phenomena have been observed by VUVATOFMS in the homogeneous ozonization reactions of pirimiphos-methyl and phenanthrene (Yang et al., 2010; Zhang et al., 2010). Additionally, $\mathrm{Ng}$ et al. (2008) indicated that $\mathrm{C}_{5} \mathrm{H}_{7} \mathrm{~N}_{2} \mathrm{O}_{9}^{-}$was a minor SOA product due to its very small chromatographic peak area, and SOA began to form after $\sim 10$ min of reaction time. Considering that the maximum acquisition time for kinetic data in the experiments was less than 300 s, it was deemed that the interferences on the acquired mass spectra caused by the reaction of gaseous isoprene with $\mathrm{NO}_{3}$ radicals could be ignored in this work. 
In the earlier studies, vanillin and 4-vinylguaiacol were identified as the products of ferulic acid through pyrolysis and microbial degradation (Fiddler et al., 1967; Lima et al., 2008; Mishra et al., 2014). Oxalic acid, vanillin, and 5-nitrovanillin were reported as the products of coniferyl aldehyde with $\mathrm{NO}_{3}$ radicals (Liu et al., 2012a). Additionally, oxalic acid and vanillin were also the ozonization products of coniferyl alcohol and coniferyl aldehyde (Net et al., 2010, 2011). Oxalic acid as the smallest dicarboxylic acid widely existed on atmospheric particles (Chebbi and Carlier, 1996). Vanillin and 4-vinylguaiacol emitted by wood smoke were always found in both particle and gas phases in ambient atmosphere (Fiddler et al., 1966; Nolte et al., 2001).

\subsection{Reaction mechanisms}

Based on the products identified, the mechanisms for the heterogeneous reaction of ferulic acid particles with $\mathrm{NO}_{3}$ radicals were proposed. The reaction mechanisms containing two main pathways are illustrated in Fig. 4.

Zhang et al. (2016) have reported that $\mathrm{NO}_{3}$ addition to the meta- position of the carbon connecting the hydroxyl group is the favored site with the lowest energy barrier for eugenol, which has a similar chemical structure as that of ferulic acid. The site is activated toward $\mathrm{NO}_{3}$ electrophilic addition by the hydroxyl, methoxyl, and olefinic groups, which could donate electron density to the benzene ring through resonance or inductive effects (Lauraguais et al., 2016). Additionally, the reactions of $\mathrm{NO}_{3}$ addition to the benzene ring of methoxyphenols were reported to be exothermic (Lauraguais et al., 2016; Zhang et al., 2016). Therefore, the nitratocyclohexadienyltype radical (intermediate I) should be formed by $\mathrm{NO}_{3}$ meta-addition to the hydroxyl substituent (Atkinson et al., 1990; Atkinson, 1991). Subsequently, the $\mathrm{NO}_{2}$ ortho-addition to the hydroxyl group produced intermediate II (Zhang et al., 2016), which was followed by the collapse of intermediate species and the loss of nitric acid to produce 5-nitroferulic acid. This process is well known as nitro-substituted reaction (Atkinson et al., 1990; Atkinson, 1991).

Pathway II was initiated by the addition of a $\mathrm{NO}_{3}$ radical on the $\mathrm{C}=\mathrm{C}$ double bond, subsequently added by an oxygen molecule to produce two nitrooxyperoxy radicals (intermediates $\mathrm{III}^{\mathrm{a}}$ and $\mathrm{III}^{\mathrm{b}}$ ) (Atkinson, 1991; Canosa-Mas et al., 1999; Klotz et al., 2004). NO

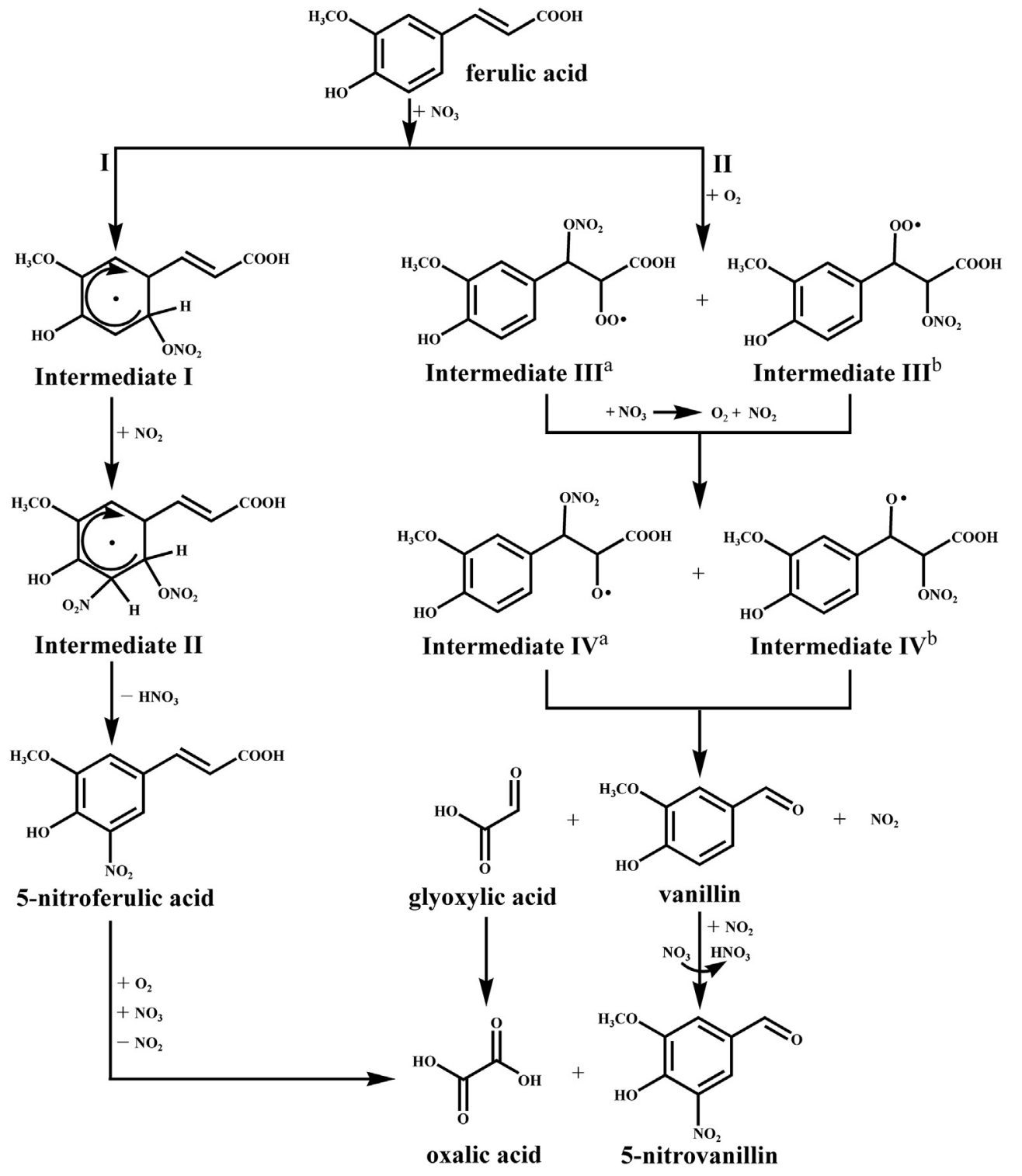

Fig. 4. Proposed pathways for the reaction between particulate ferulic acid and $\mathrm{NO}_{3}$ radicals. 
radicals should predominantly attack acrylic acid group $(-\mathrm{CH}=\mathrm{CHCOOH})$ in $\beta$-position (Berndt and Böge, 1997). Thus, the formation of intermediate III $^{\mathrm{b}}$ should be the primary channel. Through the reactions with $\mathrm{NO}_{3}$ radicals, the intermediates $\mathrm{III}^{\mathrm{a}}$ and III $^{\mathrm{b}}$ could produce the corresponding oxyl radicals (intermediates $\mathrm{IV}^{\mathrm{a}}$ and $\mathrm{IV}^{\mathrm{b}}$ ), which can then undergo $\mathrm{C}-\mathrm{C}$ bond scission to generate glyoxylic acid, $\mathrm{NO}_{2}$, and vanillin (Canosa-Mas et al., 1999; Klotz et al., 2004). The reaction of $\mathrm{NO}_{3}$ radicals with conjugated $\mathrm{C}=\mathrm{C}$ double bond was a favored way to degrade unsaturated organics and would lead to a chain scission (Atkinson, 1991; Canosa-Mas et al., 1999). On the contrary, H-abstraction from methoxyl substituent was a marginal or negligible way for reaction with $\mathrm{NO}_{3}$ radicals (Lauraguais et al., 2016). In this work, glyoxylic acid was speculated to be finally converted into oxalic acid by an addition of hydroxyl radical to the carbonyl group, which was reported previously by Net et al. (2010). Vanillin could produce 5-nitrovanillin through nitro-substituted reaction (pathway I) (Liu et al., 2012a). Through pathway II, 5-nitroferulic acid could further produce oxalic acid and 5-nitrovanillin.

The formations of 4-vinylguaiacol and caffeic acid were minor channels compared to pathways I and II, which were not included in the Fig. 4. 4-Vinylguaiacol might be produced by $\mathrm{H}$-abstract and a carbon dioxide loss from carboxyl group (Das et al., 2002; Salgado et al., 2008). Caffeic acid was speculated to be resulted from the hydroxylation by hydroxyl radicals. The similar process about 3,4dihydroxybenzoic acid formed through the ozonization of methoxyphenols has been reported (Net et al., 2010, 2011). Certainly, it is well known that hydroxyl radicals could be produced by the reactions of unsaturated organic compounds with $\mathrm{NO}_{3}$ radicals (Canosa-Mas et al., 1999; Salisbury et al., 2001).

\subsection{Heterogeneous kinetics}

In this work, the heterogeneous kinetics was studied with a mixed-phase relative rate method. The average concentration of $\mathrm{NO}_{3}$ radicals in the chamber was $\sim 5.1 \times 10^{9}$ molecules $\mathrm{cm}^{-3}$, calculated according to the loss rates of isoprene (Smith et al., 2009). The recommended rate constant of isoprene with $\mathrm{NO}_{3}$ radicals is $7.0 \times 10^{-13} \mathrm{~cm}^{3}$ molecule ${ }^{-1} \mathrm{~s}^{-1}$ (http://www.iupac-kinetic. ch.cam.ac.uk/).

The uptake coefficient can be presented as the following equation (Liu et al., 2012b):
$\gamma=\frac{\left(R_{p}{ }^{3}-R_{C}{ }^{3}\right) \rho_{F} N_{A} \eta_{F}}{3 M_{F} R_{p} D_{N_{3}} \bar{C}_{N_{3}} t}$

Here $R_{p}, R_{c}, \rho_{F}, N_{A}, \eta_{F}, M_{F}, \bar{C}_{\mathrm{NO}_{3}}$, and $D_{\mathrm{NO}_{3}}$ are respectively the particle radius $(\mathrm{cm})$, the radius of the inner core $(\mathrm{cm})$, the density of ferulic acid $\left(\mathrm{g} \mathrm{cm}^{-3}\right)$, the Avogadro's number, the consumption ratio of ferulic acid $\left(\eta_{F}=1-C_{R} / C_{0}\right.$, here $C_{0}$ and $C_{R}$ are the normalized initial and residual concentrations of ferulic acid), the molecular weight of ferulic acid $\left(\mathrm{g} \mathrm{mol}^{-1}\right)$, the average concentration of $\mathrm{NO}_{3}$ radicals (molecules $\mathrm{cm}^{-3}$ ), and the diffusion coefficient of $\mathrm{NO}_{3}$ radicals under forced diffusion in the experiment $\left(\sim 1 \mathrm{~cm}^{2} \mathrm{~s}^{-1}\right)$ (Liu et al., 2012b).

According to Eq. (1), the uptake coefficient of $\mathrm{NO}_{3}$ radicals on ferulic acid particles was calculated to be $0.17 \pm 0.02$, indicating that ferulic acid has a high reactivity toward $\mathrm{NO}_{3}$ radicals. The obtained uptake coefficient was $\sim 6$ times greater than that $(\sim 0.03)$ on nitroguaiacol surfaces (Knopf et al., 2011), while $\sim 2$ times smaller than those on particulate syringaldehyde, vanillic acid, and coniferyl aldehyde (Table 2) (Liu et al., 2012a). The concentration of $\mathrm{NO}_{3}$ radicals employed in the experiments was close to that in the troposphere at night time (Atkinson, 1991). The atmospheric lifetime of ferulic acid was $\sim 6.4 \mathrm{~h}$, calculated with a $D_{\mathrm{NO}_{3}}$ value of $0.12 \mathrm{~cm}^{2} \mathrm{~s}^{-1}$ in air (Rudick et al., 1996) and a representative $C_{\mathrm{NO}_{3}}$ value of $5 \times 10^{8}$ molecules $\mathrm{cm}^{-3}$ in the troposphere at night time (Atkinson, 1991).

The effective rate constant of heterogeneous reaction can be typically expressed as the following equation, calculated with the mixed-phase relative rate method (Huff Hartz et al., 2007; Liu et al., 2012b):

$\ln \left(C_{F} / C_{F 0}\right)=-k_{e f f} \bar{C}_{N_{3}} t$

Here $C_{F 0}$ and $C_{F}$ are the normalized initial and real-time concentrations of ferulic acid, and $k_{e f f}$ is the effective rate constant $\left(\mathrm{cm}^{3}\right.$ molecule ${ }^{-1} \mathrm{~s}^{-1}$ ).

Fig. 5 shows the plot of $\ln \left(C_{F} / C_{F 0}\right)$ versus $\bar{C}_{\mathrm{NO}_{3}} t$ for ferulic acid particles. The wall losses ( $5 \%)$ of ferulic acid particles and isoprene were ignored. Error bars were the standard deviation of duplicate experiments. The value of $k_{\text {eff }}$ was calculated to be $(1.71 \pm 0.08) \times 10^{-12} \mathrm{~cm}^{3}$ molecule ${ }^{-1} \mathrm{~s}^{-1}$ using the linear leastsquares fitting $\left(R^{2}>0.98\right)$. It was several times lower than those

Table 2

Comparison of kinetic data for heterogeneous reactions of particulate methoxyphenols with $\mathrm{O}_{3}$ and $\mathrm{NO}_{3}$ radicals.

\begin{tabular}{|c|c|c|c|c|c|c|}
\hline \multirow{2}{*}{ Compounds } & \multirow{2}{*}{ Structure } & \multirow{2}{*}{ Formula } & \multirow{2}{*}{$\mathrm{MW}\left(\mathrm{g} \mathrm{mol}^{-1}\right)$} & \multicolumn{2}{|c|}{$k_{\text {eff }}\left(\mathrm{cm}^{3}\right.$ molecule $\left.{ }^{-1} \mathrm{~s}^{-1}\right)$} & \multirow{2}{*}{$\frac{\gamma}{\mathrm{NO}_{3} \text { radicals }}$} \\
\hline & & & & $\mathrm{O}_{3}{ }^{\mathrm{a}}$ & $\mathrm{NO}_{3}$ radicals & \\
\hline $\begin{array}{l}\text { Coniferyl } \\
\text { aldehyde }\end{array}$ & & $\mathrm{C}_{10} \mathrm{H}_{10} \mathrm{O}_{3}$ & 178 & $7.2 \times 10^{-19}$ & $3.5 \times 10^{-12 b}$ & $0.28^{\mathrm{b}}$ \\
\hline Syringaldehyde & $\mathrm{H}_{3} \mathrm{CO}$ & $\mathrm{C}_{9} \mathrm{H}_{10} \mathrm{O}_{4}$ & 182 & - & $5.7 \times 10^{-12 b}$ & $0.33^{\mathrm{b}}$ \\
\hline Vanillic acid & $\mathrm{H}_{2} \mathrm{CO}_{2}$ & $\mathrm{C}_{8} \mathrm{H}_{8} \mathrm{O}_{4}$ & 168 & - & $5.2 \times 10^{-12 b}$ & $0.31^{\mathrm{b}}$ \\
\hline Ferulic acid & $\mathrm{HCO}$ & $\mathrm{C}_{10} \mathrm{H}_{10} \mathrm{O}_{4}$ & 194 & - & $1.71 \times 10^{-12 \mathrm{c}}$ & $0.17^{c}$ \\
\hline
\end{tabular}

MW, $k_{\text {eff, and }} \gamma$ are the molecular weight of compounds, effective rate constant, and uptake coefficient, respectively.

a Data derived from Net et al. (2010).

b Data derived from Liu et al. (2012a).

c This work. 


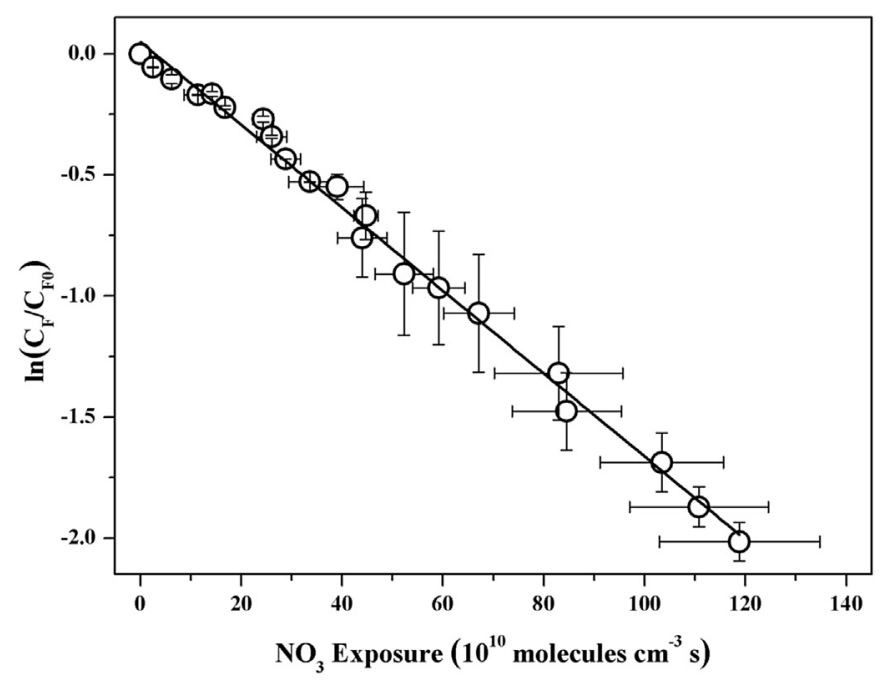

Fig. 5. Plot of $\ln \left(\mathrm{C}_{\mathrm{F}} / \mathrm{C}_{\mathrm{FO}}\right)$ vs $\mathrm{NO}_{3}$ radical exposure for particulate ferulic acid. The timeaveraged concentration of $\mathrm{NO}_{3}$ radicals was $\sim 5.1 \times 10^{9}$ molecules $\mathrm{cm}^{-3}$.

of syringaldehyde, vanillic acid, and coniferyl aldehyde with $\mathrm{NO}_{3}$ radicals reported in our previous study (Table 2) (Liu et al., 2012a); while was $\sim 6$ orders of magnitude greater than that of coniferyl aldehyde with ozone (Table 2) (Net et al., 2010). In the earlier studies, the reported reactivity of $\mathrm{NO}_{3}$ radicals with polycyclic aromatic hydrocarbons (PAHs) was much faster than that of ozone by 2-6 orders of magnitude (Shiraiwa et al., 2009; Liu et al., 2012b). Thus, $\mathrm{NO}_{3}$ radicals might have a more significant effect on ferulic acid degradation than ozone does at nighttime.

\subsection{Atmospheric implications}

Recent studies showed that methoxyphenols in the reactions with trace gaseous oxidants might have a significant contribution to SOA formation (Lauraguais et al., 2012, 2014b; Yee et al., 2013). SOA contain an important amount of organic acids, such as oxalic acid and caffeic acid identified in this work, which could serve as nucleating species for aerosol growth (Christoffersen et al., 1998). Based on the reported particle size distribution of wood smoke (Rau, 1989; Kleeman et al., 1999), it is likely that methoxyphenols are mainly adsorbed on particles with diameters below $1 \mu \mathrm{m}$ in the atmosphere. It is well known that the particle size has a negative impact on the uptake coefficient (Smith et al., 2002). Therefore, the uptake coefficient on the particle with a larger diameter in the atmosphere will be smaller, resulting in a longer lifetime. In general, the different mass loadings might have no impact on the variety of products, but larger mass loadings would result in different product yields (Gao et al., 2010) and smaller uptake coefficient (Rouvière and Ammann, 2010), subsequently lead to a longer atmospheric lifetime.

Some nitro-substituted aromatics were pointed out as the important composition of SOA from biomass burning, and might be taken as the potential tracers (Harrison et al., 2005; Kitanovski et al., 2012; Lauraguais et al., 2014a). However, the quick photolysis of ortho-nitrophenol derivates was reported (Bejan et al., 2006; 2007). Thus, whether nitro-substituted products should be used as tracers for wood smoke emissions needs to be further discussed. Through nitro-substituted reaction, the particles hygroscopicity and its activity of cloud condensation nuclei (CCN) would be affected negatively by nitro-products (Suda et al., 2014). Meanwhile, more volatile products were produced through chain scission or intermediate decomposition. Therefore, the chemical processes of methoxyphenols with $\mathrm{NO}_{3}$ radicals could lead to subsequent effects on air quality and climate.

\section{Conclusion}

In this work, the heterogeneous reaction of ferulic acid particles with $\mathrm{NO}_{3}$ radicals was investigated. Assisted with GC-MS analysis, oxalic acid, 4-vinylguaiacol, vanillin, 5-nitrovanillin, 5-nitroferulic acid, and caffeic acid were observed and confirmed as the products. The uptake coefficient of $\mathrm{NO}_{3}$ radicals on ferulic acid particles was $0.17 \pm 0.02$, calculated according to the average $\mathrm{NO}_{3}$ concentration and the consumption ratio of ferulic acid. The effective rate constant was $(1.71 \pm 0.08) \times 10^{-12} \mathrm{~cm}^{3}$ molecule ${ }^{-1} \mathrm{~s}^{-1}$, calculated using a mixed-phase relative rate method. Additionally, the reaction mechanisms were proposed to explain the formation of products. The experimental results might help further understand the chemical behaviors of ferulic acid in nighttime atmosphere.

\section{Acknowledgements}

This work was financially supported by National Natural Science Foundation of China (Grant Nos.: 21607088 and 21277155), Science and Technology Planning Project of Panzhihua, China (Grant No.: 2015TX-8), and Doctoral Fund Project of Panzhihua University (Grant No.: 0210600022). The authors would like to thank Prof. Jinian Shu and Dr. Bo Yang, who provided their genuine help to finish this work. Also, we would like to thank the reviewers for their constructive comments that help improve the manuscript.

\section{References}

Alves, C.A., Vicente, A., Monteiro, C., Goncalves, C., Evtyugina, M., Pio, C., 2011 Emission of trace gases and organic components in smoke particles from a wildfire in a mixed-evergreen forest in Portugal. Sci. Total Environ. 409 (8), 1466-1475.

Atkinson, R., 1991. Kinetics and mechanisms of the gas-phase reactions of the $\mathrm{NO}_{3}$ radical with organic compounds. J. Phys. Chem. Ref. Data. 20 (3), 459-507.

Atkinson, R., Tuazon, E.C., Arey, J., 1990. Reactions of naphthalene in $\mathrm{N}_{2} \mathrm{O}_{5}-\mathrm{NO}_{3}-\mathrm{NO}_{2}$ air mixtures. Int. J. Chem. Kinet. 22 (10), 1071-1082.

Bari, M.A., Baumbach, G., Kuch, B., Scheffknecht, G., 2010. Temporal variation and impact of wood smoke pollution on a residential area in southern Germany. Atmos. Environ. 44 (31), 3823-3832.

Bejan, I., Abd El Aal, Y., Barnes, I., Benter, T., Bohn, B., Wiesen, P., Kleffmann, J., 2006 The photolysis of ortho-nitrophenols: a new gas phase source of HONO. Phys. Chem. Chem. Phys. 8 (17), 2028-2035.

Bejan, I., Barnes, I., Olariu, R., Zhou, S., Wiesen, P., Benter, T., 2007. Investigations on the gas-phase photolysis and $\mathrm{OH}$ radical kinetics of methyl-2-nitrophenols. Phys. Chem. Chem. Phys. 9 (42), 5686-5692.

Berndt, T., Böge, O., 1997. Gas-phase reaction of $\mathrm{NO}_{3}$ radicals with isoprene: a kinetic and mechanistic study. Int. J. Chem. Kinet. 29 (10), 755-765.

Bolling, A.K., Pagels, J., Yttri, K.E., Barregard, L., Sallsten, G., Schwarze, P.E., Boman, C., 2009. Health effects of residential wood smoke particles: the importance of combustion conditions and physicochemical particle properties. Part. Fibre Toxicol. 6 http://dx.doi.org/10.1186/1743-8977-6-29.

Canosa-Mas, C.E., Carr, S., King, M.D., Shallcross, D.E., Thompson, K.C., Wayne, R.P. 1999. A kinetic study of the reactions of $\mathrm{NO}_{3}$ with methyl vinyl ketone, methacrolein, acrolein, methyl acrylate and methyl methacrylate. Phys. Chem. Chem. Phys. 1 (18), 4195-4202.

Chebbi, A., Carlier, P., 1996. Carboxylic acids in the troposphere, occurrence, sources, and sinks: a review. Atmos. Environ. 30 (24), 4233-4249.

Christoffersen, T.S., Hjorth, J., Horie, O., Jensen, N.R., Kotzias, D., Molander, L.L. Neeb, P., Ruppert, L., Winterhalter, R., Virkkula, A., Wirtz, K., Larsen, B.R., 1998. cis-Pinic acid, a possible precursor for organic aerosol formation from ozonolysis of $\alpha$-pinene. Atmos. Environ. 32 (10), 1657-1661.

Coeur-Tourneur, C., Cassez, A., Wenger, J.C., 2010. Rate coefficients for the gas-phase reaction of hydroxyl radicals with 2-methoxyphenol (guaiacol) and related compounds. J. Phys. Chem. A. 114 (43), 11645-11650.

Das, J.P., Sinha, P., Roy, S., 2002. A nitro-Hunsdiecker reaction: from unsaturated carboxylic acids to nitrostyrenes and nitroarenes. Org. Lett. 4 (18), 3055-3058.

Ezzati, M., Kammen, D.M., 2002. The health impacts of exposure to indoor air pollution from solid fuels in developing countries: knowledge, gaps, and data needs. Environ. Health. Perspect. 110 (11), 1057-1068.

Fiddler, W., Doerr, R.C., Wasserman, A.E., Salay, J.M., 1966. Composition of hickory sawdust smoke. furans and phenols. J. Agric. Food Chem. 14 (6), 659-662.

Fiddler, W., Parker, W.E., Wasserman, A.E., Doerr, R.C., 1967. Thermal decomposition 
of ferulic acid. J. Agric. Food Chem. 15 (5), 757-761.

Gao, S.K., Zhang, Y., Li, Y., Meng. J.W., He, H., Shu, J.N., 2008. A comparison between the vacuum ultraviolet photoionization time-of-flight mass spectra and the GC MS total ion chromatograms of polycyclic aromatic hydrocarbons contained in coal soot and multi-component PAH particles. Int. J. Mass Spectrom. 274 (1-3), 64-69.

Gao, Y.Q., Hall, W.A., Johnston, M.V., 2010. Molecular composition of monoterpene secondary organic aerosol at low mass loading. Environ. Sci. Technol. 44 (20), 7897-7902.

Harrison, M.A.J., Barra, S., Borghesi, D., Vione, D., Arsene, C., Olariu, R.I., 2005 Nitrated phenols in the atmosphere: a review. Atmos. Environ. 39 (2), 231-248. http://www.iupac-kinetic.ch.cam.ac.uk/. Accessed June 6, 2015.

Huff Hartz, K.E., Weitkamp, E.A., Sage, A.M., Donahue, N.M., Robinson, A.L., 2007. Laboratory measurements of the oxidation kinetics of organic aerosol mixtures using a relative rate constants approach. J. Geophys. Res.-Atmos 112. http:// dx.doi.org/10.1029/2006jd007526.

Ide, T., Nakayama, T., Takahashi, K., Matsumi, Y., 2008. Thermal decomposition rate of $\mathrm{N}_{2} \mathrm{O}_{5}$ measured by cavity ring-down spectroscopy. Int. J. Chem. Kinet. 40 (10), 679-684.

Karagulian, F., Rossi, M.J., 2005. The heterogeneous chemical kinetics of $\mathrm{NO}_{3}$ on atmospheric mineral dust surrogates. Phys. Chem. Chem. Phys. 7 (17), 3150-3162.

Kitanovski, Z., Groić, I., Vermeylen, R. Claeys, M., Maenhaut, W., 2012. Liquid chromatography tandem mass spectrometry method for characterization of monoaromatic nitro-compounds in atmospheric particulate matter. J. Chromatogr. A 1268 (23), 35-43.

Kleeman, M.J., Schauer, J.J., Cass, G.R., 1999. Size and composition distribution of fine particulate matter emitted from wood burning, meat charbroiling, and cigarettes. Environ. Sci. Technol. 33 (20), 3516-3523.

Klotz, B., Barnes, I., Imamura, T. 2004. Product study of the gas-phase reactions of $\mathrm{O}_{3}, \mathrm{OH}$ and $\mathrm{NO}_{3}$ radicals with methyl vinyl ether. Phys. Chem. Chem. Phys. 6 (8), 1725-1734.

Knopf, D.A., Forrester, S.M., Slade, J.H., 2011. Heterogeneous oxidation kinetics of organic biomass burning aerosol surrogates by $\mathrm{O}_{3}, \mathrm{NO}_{2}, \mathrm{~N}_{2} \mathrm{O}_{5}$, and $\mathrm{NO}_{3}$. Phys Chem. Chem. Phys. 13 (47), 21050-21062.

Lauraguais, A., Coeur-Tourneur, C., Cassez, A., Deboudt, K., Fourmentin, M. Choël, M., 2014a. Atmospheric reactivity of hydroxyl radicals with guaiacol (2methoxyphenol), a biomass burning emitted compound: secondary organic aerosol formation and gas-phase oxidation products. Atmos. Environ. 86, 155-163.

Lauraguais, A., Coeur-Tourneur, C., Cassez, A., Seydi, A., 2012. Rate constant and secondary organic aerosol yields for the gas-phase reaction of hydroxyl radicals with syringol (2,6-dimethoxyphenol). Atmos. Environ. 55, 43-48.

Lauraguais, A., Bejan, I., Barnes, I., Wiesen, P., Coeur-Tourneur, C., Cassez, A., 2014b. Rate coefficients for the gas-phase reaction of chlorine atoms with a series of methoxylated aromatic compounds. J. Phys. Chem. A 118 (10), 1777-1784.

Lauraguais, A., Zein, A.E., Coeur-Tourneur, C., Obeid, E., Cassez, A., Rayez, M.T. Rayez, J.C., 2016. Kinetic study of the gas-phase reactions of nitrate radicals with methoxyphenol compounds: experimental and theoretical approaches. J. Phys. Chem. A 120 (17), 2691-2699.

Lima, C.F., Barbosa, L.C.A., Marcelo, C.R., Silverio, F.O., Colodette, J.L., 2008. Comparison between analytical pyrolysis and nitrobenzene oxidation for determination of syringyl/guaiacyl ratio in Eucalyptus spp. lignin. Bioresources 3 (3), 701-712.

Liu, C.G., Zhang, P., Wang, Y.F., Yang, B., Shu, J.N., 2012a. Heterogeneous reactions of particulate methoxyphenols with $\mathrm{NO}_{3}$ radicals: kinetics, products, and mechanisms. Environ. Sci. Technol. 46 (24), 13262-13269.

Liu, C.G. Zhang, P., Yang, B., Wang, Y.F., Shu, J.N., 2012b. Kinetic studies of heterogeneous reactions of polycyclic aromatic hydrocarbon aerosols with $\mathrm{NO}_{3}$ radicals. Environ. Sci. Technol. 46 (14), 7575-7580.

Mishra, S., Sachan, A., Vidyarthi, A.S., Sachan, S.G., 2014. Transformation of ferulic acid to 4-vinylguaiacol as a major metabolite: a microbial approach. Rev. Environ. Sci. Biotechnol. 13 (4), 377-385.

Naeher, L.P., Michael, B., Michael, L., Zelikoff, J.T., Simpson, C.D., Koenig, J.Q. Smith, K.R., 2007. Woodsmoke health effects: a review. Inhal. Toxicol. 19 (1), 67-106.

Net, S., Alvarez, E.G., Balzer, N., Wortham, H., Zetzsch, C., Gligorovski, S., 2010 Photolysis and heterogeneous reaction of coniferyl aldehyde adsorbed on silica particles with ozone. Chemphyschem 11 (18), 4019-4027.

Net, S., Alvarez, E.G., Gligorovski, S., Wortham, H., 2011. Heterogeneous reactions of ozone with methoxyphenols, in presence and absence of light. Atmos. Environ. 45 (18), 3007-3014.
Ng, N.L., Kwan, A.J., Surratt, J.D., Chan, A.W.H., Chhabra, P.S., Sorooshian, A., Pye, H.O.T., Crounse, J.D., Wennberg, P.O., Flagan, R.C., Seinfeld, J.H., 2008. Secondary organic aerosol (SOA) formation from reaction of isoprene with nitrate radicals $\left(\mathrm{NO}_{3}\right)$. Atmos. Chem. Phys. 8 (14), 4117-4140.

Nolte, C.G., Schauer, J.J., Cass, G.R., Simoneit, B.R.T., 2001. Highly polar organic compounds present in wood smoke and in the ambient atmosphere. Environ. Sci. Technol. 35 (10), 1912-1919.

O'Neill, E.M., Kawam, A.Z., Ry, D.A.V., Hinrichs, R.Z., 2014. Ozonolysis of surfaceadsorbed methoxyphenols: kinetics of aromatic ring cleavage vs. alkene sidechain oxidation. Atmos. Chem. Phys. 14 (1), 47-60.

Ofner, J., Krüger, H.-U., Grothe, H., Schmitt-Kopplin, P., Whitmore, K., Zetzsch, C., 2011. Physico-chemical characterization of SOA derived from catechol and guaiacol-a model substance for the aromatic fraction of atmospheric HULIS. Atmos. Chem. Phys. 11 (1), 1-15.

Rau, J.A., 1989. Composition and size distribution of residential wood smoke particles. Aerosol Sci. Technol. 10 (1), 181-192.

Rouvière, A., Ammann, M., 2010. The effect of fatty acid surfactants on the uptake of ozone to aqueous halogenide particles. Atmos. Chem. Phys. 10 (23), $11489-11500$.

Rudick, Y., Talukdar, R.K., Imamura, T., Fox, R.W., Ravishankara, A.R., 1996. Uptake of $\mathrm{NO}_{3}$ on KI solutions: rate coefficient for the $\mathrm{NO}_{3}+\mathrm{I}^{-}$reaction and gas-phase diffusion coefficients for $\mathrm{NO}_{3}$. Chem. Phys. Lett. 261 (4-5), 467-473.

Salgado, M.S., Monedero, E., Villanueva, F., Martin, P., Tapia, A., Cabanas, B., 2008. Night-time atmospheric fate of acrolein and crotonaldehyde. Environ. Sci. Technol. 42 (7), 2394-2400.

Salisbury, G., Rickard, A.R., Monks, P.S., Allan, B.J., Bauguitte, S., Penkett, S.A., Carslaw, N., Lewis, A.C., Creasey, D.J., Heard, D.E., Jacobs, P.J., Lee, J.D., 2001. Production of peroxy radicals at night via reactions of ozone and the nitrate radical in the marine boundary layer. J. Geophys. Res.-Atmos 106 (D12), 12669-12687.

Shiraiwa, M., Garland, R.M., Pöschl, U., 2009. Kinetic double-layer model of aerosol surface chemistry and gas-particle interactions (K2-SURF): degradation of polycyclic aromatic hydrocarbons exposed to $\mathrm{O}_{3}, \mathrm{NO}_{2}, \mathrm{H}_{2} \mathrm{O}, \mathrm{OH}$ and $\mathrm{NO}_{3}$. Atmos. Chem. Phys. 9 (24), 9571-9586.

Shu, J.N., Gao, S.K., Li, Y., 2008. A VUV photoionization aerosol time-of-flight mass spectrometer with a RF-powered VUV lamp for laboratory-based organic aerosol measurements. Aerosol Sci. Tech. 42 (2), 110-113.

Smith, G.D., Woods, E., DeForest, C.L., Baer, T., Miller, R.E., 2002. Reactive uptake of ozone by oleic acid aerosol particles: application of single-particle mass spectrometry to heterogeneous reaction kinetics. J. Phys. Chem. A 106 (35), 8085-8095.

Smith, J.D., Kroll, J.H., Cappa, C.D., Che, D.L., Liu, C.L., Ahmed, M., Leone, S.R., Worsnop, D.R., Wilson, K.R., 2009. The heterogeneous reaction of hydroxyl radicals with sub-micron squalane particles: a model system for understanding the oxidative aging of ambient aerosols. Atmos. Chem. Phys. 9 (9), 3209-3222.

Suda, S.R., Petters, M.D., Yeh, G.K., Strollo, C., Matsunage, A., Faulhaber, A., Ziemann, P.J., Prenni, A.J., Carrico, C.M., Sullivan, R.C., Kreidenweis, S.M., 2014 Influence of functional groups on organic aerosol cloud condensation nucleus activity. Environ. Sci. Technol. 48 (17), 10182-10190.

Wayne, R.P., Barnes, I., Biggs, P., Burrows, J.P., Canosamas, C.E., Hjorth, J., Lebras, G., Moortgat, G.K., Perner, D., Poulet, G., Restelli, G., Sidebottom, H., 1991. The nitrate radical: physics, chemistry, and the atmosphere. Atmos. Environ. A- Gen. 25 (1), 1-203.

Yang, B., Zhang, Y., Meng, J.W., Gan, J., Shu, J.N., 2010. Heterogeneous reactivity of suspended pirimiphos-methyl particles with ozone. Environ. Sci. Technol. 44 (9), 3311-3316.

Yang, B., Zhang, H.X., Wang, Y.F., Zhang, P., Shu, J.N., Sun, W.Q., Ma, P.K., 2016. Experimental and theoretical studies on gas-phase reactions of $\mathrm{NO}_{3}$ radicals with three methoxyphenols: guaiacol, creosol, and syringol. Atmos. Environ. $125,243-251$

Yee, L.D., Kautzman, K.E., Loza, C.L., Schilling, K.A., Coggon, M.M., Chhabra, P.S., Chan, M.N., Chan, A.W.H., Hersey, S.P., Crounse, J.D., Wennberg, P.O., Flagan, R.C. Seinfeld, J.H., 2013. Secondary organic aerosol formation from biomass burning intermediates: phenol and methoxyphenols. Atmos. Chem. Phys. 13 (2), 8019-8043.

Zhang, Y., Yang, B., Meng, J.W., Gao, S.K., Dong, X.Y., Shu, J.N., 2010. Homogeneous and heterogeneous reactions of phenanthrene with ozone. Atmos. Environ. 44 (5), 697-702.

Zhang, H.X., Yang, B., Wang, Y.F., Shu, J.N., Zhang, P., Ma, P.K., Li, Z., 2016. Gas-phase reactions of methoxyphenols with $\mathrm{NO}_{3}$ radicals: kinetics, products, and mechanisms. J. Phys. Chem. A 120 (8), 1213-1221. 